\title{
HADIS MUTTAFAQ `ALAIH DALAM KITAB RIYÂDH AL-SHÂLIHînN
}

\author{
Mujiyo \\ Fakultas Ushuluddin UIN Sunan Gunung Djati Bandung \\ J1. AH. Nasution No. 105 Cibiru, Bandung \\ E-Mail: Masmujionur@yahoo.co.id
}

\begin{abstract}
In the study of the science of hadith editors the difference of riwayah is important think. And the hadith scholars agree assume two distinct history wording as two hadith. They are not allowed to change the editorial tradition in a book by adding or subtracting one word or one with fixed attribute the tradition is to the book. Therefore it should be muttafaq'alaih hadith contained in the books of hadith really set the wording contained in Saheeh al-Bukhari and Sahih Muslim. If a tradition called 'Muttafaq alaih wording could not be found on the original, with the same editorial, the inclusion of the tradition is a violation of the code of ethics of narration hadith. The last thing is happening in the hadith " Innama al-a "mal bi al-Niyyat" at the beginning of the book Al-Arba'in al-Nawawiyyah and book Riyadh al-Shalihin of Al-Nawawi (d. $676 \mathrm{H})$. These findings are reason enough to investigate hither the traditions muttafaq 'alaih in Riyadh al-Shalihin given in this book the number of hadith muttafaq' alaih reached about half of the number of hadith contained therein, which is about 900 Hadith 1800 Hadith. Preliminary observations indicate that the text of the traditions muttafaq 'alaih can be classified into three, namely traditions were really the same as the text of the hadith in Sahih al-Bukhari and Sahih Muslim, hadith which is just the same with one of them or an excerpt from it, and the hadith which is totally different from both. So with this study are expected to be found cases of 'traditions muttafaq laih third category varied and is a violation of the code of conduct Hadith narration by the author Riyadh al-Shalihin. Nevertheless these findings can be used as materials for the formulation of criteria muttafaq 'alaih traditions other than the two criteria that have been agreed. With the discovery of the formulation of criteria traditions muttafaq 'alaih third category in the book of Riyadh al-Shalihin, it will produce a new theory for the study of hadith muttafaq' alaih which have never been questioned and questioned. The theory can in turn make it easier for authors of scientific papers in the hadith refers muttafaq 'alaih to the primary source.
\end{abstract}

Keywords: Hadith; Muttafaq 'alaih; Nawawi; Riyadhus Shalihin; Riwayah.

\begin{abstract}
Abstrak
Dalam kajian ilmu hadis riwayah perbedaan redaksi hadis merupakan hal yang sangat diperhatikan dan para ulama hadis sepakat menganggap dua riwayat yang berbeda redaksinya sebagai dua hadis.t Mereka tidak memperbolehkan mengubah redaksi hadis di satu kitab dengan menambah atau mengurangi satu kata maupun satu hurufpun dengan tetap menisbatkan hadis itu kepada kitab tersebut. Oleh karena itu mestinya hadis muttafaq `alaih yang terdapat dalam kitab-kitab himpunan hadis benar-benar redaksinya terdapat dalam Shahih al-Bukhari dan Shahih Muslim . Apabila suatu hadis yang disebut muttafaq `alaih redaksinya tidak bisa ditemukan pada sumber aslinya dengan redaksi yang sama, maka pencantuman hadis itu merupakan pelanggaran kode etik periwayatan hadis. Hal terakhir ini terjadi pada hadis "Innamâ al-a 'mâl bi al-niyyât" pada awal kitab Al-Arba î̀n al-Nawawiyyah dan kitab Riyâdh al-Shâlihîn karya Al-Nawawi (w. 676 H). Temuan ini menjadi alasan cukup kuat untuk meneliti lebih lanjut hadishadis muttafaq `alaih di dalam Riyâdh al-Shâlihîn mengingat dalam kitab ini jumlah hadis muttafaq `alaih mencapai sekitar separoh dari jumlah hadis yang tercantum di dalamnya, yaitu sekitar 900 hadis dari 1800 hadis. Hasil penelitian pendahuluan menunjukkan bahwa teks hadis-hadis muttafaq `alaih dapat diklasifikasi menjadi tiga, yaitu hadis yang benar-benar sama dengan teks hadis dalam Shahih al-Bukhari dan Shahih Muslim, hadis yang hanya sama dengan salah satunya atau merupakan kutipan darinya, dan hadis yang berbeda sama sekali dengan keduanya. Maka dengan penelitian ini diharapkan dapat ditemukan kasus hadis muttafaq `laih katagori ketiga yang bervariasi dan merupakan pelanggaran kode etik periwayatan hadis yang dilakukan penulis Riyadh al-Shalihin. Meskipun demikian temuan ini dapat dijadikan bahan perumusan kriteria hadis muttafaq `alaih selain dua kriteria yang sudah
\end{abstract}


disepakati.

Dengan ditemukannya rumusan kriteria-kriteria hadis muttafaq `alaih katagori ketiga dalam kitab Riyadh alShalihin, maka akan dihasilkan teori baru bagi kajian hadis muttafaq `alaih yang selama ini tidak pernah dipersoalkan dan dipertanyakan. Teori tersebut pada gilirannya dapat mempermudah para penulis karya ilmiah dalam merujuk hadis muttafaq `alaih kepada sumber primernya.

Kata Kunci: Hadith; Muttafaq 'alaih; Nawawi; Riyadhus Shalihin; Riwayah

\section{A. PENDAHULUAN}

Istilah hadis muttafaq 'alaih merupakan hadis dengan tingkat otentisitas yang tertinggi. Masyarakat Muslim meyakini bahwa hadis tersebut terdapat dalam dua kitab hadis paling shahih, yaitu Shahih alBukhari dan Shahih Muslim dengan redaksi yang sama. Lebih-lebih apabila informasi tentang hadis muttafaq alaih itu mereka peroleh dari kitab himpunan hadis yang telah menjadi referensi para tokoh agama, seperti dari kitab Al-Arba in al-Nawawiyyah atau Riyadh al-Shalihin karya Abu Zakariyya Yahya bin Syaraf al-Nawawi (w. 676 H). Tidak terbayangkan oleh mereka bahwa hadis yang mereka kenal itu ternyata tidak tercantum dalam kedua kitab hadis paling shahih tersebut atau salah satunya, seperti hadis "Innamâ al-a 'mâl bi al-niyyât" yang tercantum sebagai hadis pertama dalam kitab Al-Arba in al-Nawawiyyah dan Riyadh alShalihin itu sebenarnya tidak ada dalam Shahih al-Bukhari dan Shahih Muslim dengan redaksi yang sepenuhnya sama seperti itu.

Istilah hadis muttafaq 'alaih sudah sangat lama dipergunakan di kalangan ulama hadis, sejak Imam Al-Baghawi (w. 510 H) dalam Syarh al-Sunnah, Al-Nawawi (w. 676 H) dalam Riyadh al-Shalihin dan Al-Arba in alNawawiyyah, dan Ibn Hajar Al-Asqalani (w. 952 H) dalam Bulugh al-Maram. Adapun Majd al-Din Abu al-Barakat Ibn Taymiyyah (w. 652 H) dalam Muntaqa al-Akhbar menggunakan istilah tersebut untuk hadis yang diriwayatkan Al-Bukhari, Muslim, dan Ahmad bin Hanbal (w. 241 H).

Akan tetapi dalam kitab-kitab yang mencamtumkan hadis-hadis muttafaq `aqlaih atau muttafaq 'ala shihhatih tersebut tidak menjelaskan kriteria pengutipannya. Sehingga ketika Muhammad Fu'ad Abdul Baqi diminta oleh Sayyid Muhammad alHalabi, Direktur Penerbit Dar Ihya' al-Kutub al-'Arabiyyah, untuk menyusun $\mathrm{Al}-\mathrm{Lu}$ 'lu' wa al- Marjan tentang hadis-hadis muttafaq alaih, ia tidak mendapatkan kriteria yang jelas dari contoh para penulis terdahulu. Ia menyatakan dengan tegas tidak memperoleh kriteria yang pasti dalam kitab Bulugh alMaram karya Ibn Hajar al-'Asqalani dan kitab Al-Arba in al-Nawawiyyah karya AlNawawi. Pada akhirnya ia menuliskan dengan mencantumkan hadis-hadis dari Shahih al-Bukhari yang sesuai redaksi atau maknanya dengan hadis-hadis dalam Shahih Muslim . Sementara itu judul-judul bab yang digunakan dikutipnya dari kitab Shahih Muslim . dalam muqadimah kitabnya itu.

Kitab Riyadh al-Shalihin dan Bulugh alMaram merupakan kitab hadis yang paling banyak dikaji, baik di masyarakat perguruan tinggi, di masyarakat pesantren, maupun di masyarakat awam. Oleh karena itu, kriteria penulisan hadis-hadis muttafaq 'alaih dalam kedua kitab tersebut atau salah satunya perlu ditelusuri untuk selanjutnya dijadikan 
sebagai panduan dalam mengkajinya dan melaksanakan penelitian lebih lanjut.

\section{B. PEMBAHASAN}

Kitab Riyadh al-Shalihin yang disusun oleh Imam Abu Zakariyya Yahya bin Syaraf al-Nawawi (w. 676 H) adalah kitab himpunan hadis, yaitu kitab hadis yang hadis-hadis dikutip dari berbagai kitab hadis sumber primer atau kitab induk seperti alkutub al-sittah. Hadis-hadis yang dihimpunnya merupakan hadis-hadis akidah dan akhlaq. Jumlah hadis dalam kitab ini

\begin{tabular}{|c|c|c|c|c|c|}
\hline No. & \multicolumn{2}{|c|}{ SAMA } & $\begin{array}{c}\text { AL- } \\
\text { BUKHARI }\end{array}$ & MUSLIM & BERBEDA \\
\hline 1 & $3 / 3$ & $62 / 142$ & $2 / 2$ & $8 / 10$ & $1 / 1$ \\
\hline 2 & $5 / 6$ & $64 / 146$ & $10 / 12$ & $12 / 20$ & $4 / 4$ \\
\hline 3 & $6 / 8$ & $65 / 147$ & $11 / 14$ & $13 / 21$ & $17 / 29$ \\
\hline 4 & $7 / 9$ & $66 / 154$ & $14 / 23$ & $16 / 26$ & $27 / 52$ \\
\hline 5 & $9 / 11$ & $67 / 156$ & $15 / 24$ & $22 / 42$ & $30 / 56$ \\
\hline 6 & $19 / 35$ & $68 / 160$ & $18 / 31$ & $23 / 44$ & $34 / 64$ \\
\hline 7 & $20 / 36$ & $70 / 162$ & $25 / 46$ & $26 / 51$ & $38 / 75$ \\
\hline 8 & $21 / 40$ & $71 / 165$ & $31 / 58$ & $33 / 60$ & $41 / 81$ \\
\hline 9 & $24 / 45$ & $72 / 166$ & $39 / 78$ & $37 / 74$ & $52 / 115$ \\
\hline 10 & $28 / 53$ & $76 / 175$ & $40 / 80$ & $45 / 99$ & $69 / 161$ \\
\hline 11 & $29 / 54$ & $78 / 180$ & $44 / 98$ & $57 / 125$ & $73 / 167$ \\
\hline 12 & $32 / 59$ & $79 / 182$ & $46 / 101$ & $75 / 169$ & $95 / 223$ \\
\hline 13 & $35 / 65$ & $80 / 183$ & $49 / 109$ & $81 / 168$ & \\
\hline 14 & $36 / 69$ & $82 / 189$ & $50 / 110$ & $84 / 198$ & \\
\hline 15 & $42 / 89$ & $83 / 190$ & $51 / 114$ & $96 / 224$ & \\
\hline 16 & $43 / 90$ & $85 / 199$ & $63 / 143$ & $98 / 226$ & \\
\hline 17 & $47 / 103$ & $86 / 200$ & $75 / 172$ & $99 / 227$ & \\
\hline 18 & $48 / 104$ & $87 / 206$ & $77 / 177$ & & \\
\hline 19 & $53 / 117$ & $88 / 207$ & $100 / 228$ & & \\
\hline 20 & $54 / 112$ & $89 / 208$ & & & \\
\hline 21 & $55 / 123$ & $90 / 209$ & & & \\
\hline 22 & $56 / 124$ & $91 / 210$ & & & \\
\hline 23 & $58 / 126$ & $92 / 213$ & & & \\
\hline 24 & $59 / 132$ & $93 / 219$ & & & \\
\hline 25 & $60 / 139$ & $94 / 222$ & & & \\
\hline 26 & $61 / 141$ & $97 / 225$ & & & \\
\hline & & & & & \\
\hline & $941 a h$ & & & \\
\hline
\end{tabular}

adalah 1896 buah dan menurut Al-Nawawi seluruhnya shahih dan dikutip dari kitabkitab hadis yang disepakati ketinggian kualitasnya. Dari hadis-hadis tersebut terdapat 900 hadis lebih hadis muttafaq 'alaih. ${ }^{1}$ Hal ini menunjukkan bahwa hampir separoh dari hadis dalam kitab Riyadh alShalihin merupakan hadis muttafaq `alaih.

Dari 100 hadis muttafaq 'alaih pertama dalam kitab Riyadh al-Shalihin yang terdapat di antara hadis pertama sampai dengan hadis ke-228 diteliti faktor kesamaan dan ketidaksamaan redaksinya dengan redaksi hadis tersebut dalam kitab Riyadh al-Shalihin ditemukan bahwa $52 \%$ di antaranya benarbenar sama dengan redaksi dalam Shahih alBukhari dan Shahih Muslim, $19 \%$ di antaranya sesuai dengan redaksi Shahih AlBukhari, $17 \%$ di antaranya sesuai dengan redaksi Shahih Muslim, dan $12 \%$ tidak sama dengan redaksi dalam Shahih al-Bukhari dan Shahih Muslim , sebagaimana dapat dilihat pada tabel berikut:

Keterangan: Angka-angka yang disertai garis miring menunjukkan nomor urut perolehan hadis muttafaq 'alaih dalam Riyadh al-Shalihin terletak pada nomor urut hadis dalam Riyadh al-Shalihin

Dalam kajian ilmu hadis riwayah penyebutan hadis-hadis dalam katagori pertama sebagai hadis-hadis muttafaq `alaih adalah tepat dan tidak menimbulkan masalah berikutnya, ${ }^{2}$ baik untuk keperluan

1 Jumlah ini diperoleh melalui penelusuran dengan Maktabah Syamilah. Penelusuran dilakukan dengan menggunakan kata kunci متفق عليه dalam kitab Riyadh al-Shalihin, maka kata kunci tersebut muncul 906 kali. Hanya saja kata kunci tersebut dalam beberapa halaman yang ditunjuk muncul lebih dari satu kali. Maka kesimpulan sementara bahwa jumlah hadis muttafaq 'alaih dalam Riyadh al-Shalihin lebih dari 900 hadis.

2 Yang dimaksud adalah masalah dalam perpektif ilmu hadis riwayah yang sangat menghargai ketepatan redaksi. Dengan berpegang kepada satu redaksi hadis yang demikian peneliti dan pensyarah tidak perlu terlalu khawatir terjebak dalam redaksi hadis tersebut. 
periwayatan lebih lanjut ataupun untuk penulisan karya ilmiah, karena hadis-hadis tersebut secara lafal dan makna benar-benar merupakan riwayat Al-Bukhari dan Muslim. Akan tetapi dalam penulisan karya karya ilmiah, khususnya dalam tema hadis dan ilmu hadis atau di lingkungan jurusan Tafsir Hadits dan Ilmu Hadits- harus dikembalikan kepada sumber utamanya, yaitu Shahih alBukhari dan Shahih Muslim, tidak cukup dengan sumber kedua, yaitu Riyadh alShalihin. Demikian juga hadis-hadis dalam katagori kedua dan ketiga dalam perpektif ilmu hadis dirayah dapat dianggap sebagai hadis-hadis muttafaq 'laih dan menempati posisi hadis dengan kualitas tertinggi. Tapi dalam perpektif ilmu riwayah masih mungkin menimbulkan masalah dalam hal periwayatan hadis lebih lanjut, terutama dalam masalah penulisan karya ilmiah di bidang hadis.

Adapun hadis-hadis dalam katagori keempat dalam perspektif ilmu hadis riwayah merupakan hasil pengutipan dan periwayatan yang secara teori menyalahi kode etik periwayatan hadis dari kitab. Secara umum para ulama hadis melarang periwayatan hadis dari kitab hadis kecuali secara lafal, artinya redaksi hadis yang diriwayatkan harus sama dengan redaksi hadis yang terdapat dalam kitab sumbernya. Oleh karena itu hadishadisnya tidak sepenuhnya dapat dikatakan sebagai hadis muttafaq `alaih dengan segala kelebihannya.

Sementara itu Al-Nawawi sangat diakui kompetensinya di bidang ilmu hadis dan sangat dihargai pendapat serta tindakannya. Akan tetapi tidak berarti bahwa tindakannya kali ini menjadi legitimasi bagi pelanggaran kode etik periwayatan hadis dari kitab. Artinya hadis-hadis muttafaq `alaih dalam katgori keempat dianalisa berdasarkan pendapat Al-Nawawi dalam periwayatan hadis, yaitu ia memperbolehkan periwayatan hadis dengan makna, memotong atau meringkas hadis, dan penggabungan dua hadis. Sebenarnya kebolehan tiga hal terakhir ini tidak hanya dalam pendapat Al-Nawawi. Tapi semua sepakat, termasuk Al-Nawawi, bahwa ketiga hal ini tidak boleh dilakukan dalam meriwayatkan hadis dari kitab hadis untuk disampaikan secara langsung kepada masyarakat ataupun untuk ditulis ke dalam buku atau makalah.

\section{Teori Hadis Muttafaq 'Alaih}

Riba Istilah hadis muttafaq `alaih sudah sangat lama dipergunakan ahli hadis dan masyarakat Muislim seakan telah memahaminya dengan baik. Akan tetapi sebenarnya secara teori kajian mengenai hal itu masih sangat jarang. Kitab-kitab ilmu hadis yang disusun sejak istilah muttafaq alaih digunakan hingga kitab ilmu hadis yang disusun oleh para ulama hadis kontemporer sekalipun tidak membahasnya kecuali hanya sedikit. Ibn al-Shalah (w. 643 $\mathrm{H})$ semula menggunakan istilah muttafaq alaih sebagai istilah bagi hadis shahih yang padanya terpenuhi syarat-syarat keshahihan hadis dengan sempurna, tanpa membatasi hadis riwayat ulama tertentu. Namun kemudian ia menyederhanakan istilah tersebut sebagai hadis yang disepakati keshahihannya oleh Al-Bukhari dan Muslim setelah disepakati bahwa kitab mereka merupakan kitab hadis yang paling shahih.

Faktor kesamaan yang dimaksud ada dua, yaitu faktor redaksi dan faktor makna. Sementara itu faktor kesamaan atau perbedaan sanad dalam Shahih al-Bukhari dan Shahih Muslim tidak menjadi pertimbangan bagi penyebutan hadis muttafaq `alaih. 
Sebagai istilah, maka muttafaq `alaih tidak sepenuhnya bisa dipahami secara harfiah, melainkan harus mengikuti maksud dari orang yang membuat istilah itu dan masyarakat yang menggunakannya. Imam Al-Baghawi (w. 510 H) dalam Syarh alSunnah menggunakan istilah muttafaq 'alaih atau muttafaq 'ala shihhatihi tersebut dengan disertai penjelasan bahwa hadis yang bersangkutan diriwayatkan oleh Muhammad (Al-Bukhari) dan Muslim atau salah satunya. Demikian juga Imam Al-Nawawi (w. $676 \mathrm{H}$ ) dalam Riyadh al-Shalilih dan Al-Arba in alNawa-wiyyah juga menggunakan istilah tersebut untuk maksud yang sama, dengan mengemukakan maksudnya itu pada awal penggunaan istilah tersebut, yaitu hadis innamal a `malu bi al-niyyat ${ }^{3}$. Ibn Hajar AlAsqalani (w. 952 H) dalam Bulugh al-Maram menjelaskan maksud penggunaan istilah muttafaq ‘alaih pada muqaddimahnya. Demikian juga Abu al-Barakat Ibn Taymiyyah (w. $652 \mathrm{H}$ ) dalam Muntaqa alAkhbar menjelaskan maksud penggunaan istilah tersebut pada muqaddimahnya, yaitu untuk hadis yang diriwayatkan Al-Bukhari, Muslim, dan Ahmad bin Hanbal (w. 241 H).

Dalam tradisi ulama hadis yang dimaksud dengan ungkapan "akhrajahu al-Bukhari wa Muslim" atau "muttafaq 'alaih", atau "muttafaq “ala shihhatihi" (hadis yang diriwayatkan Al-Bukhari dan Muslim atau hadis yang disepakati keshahihannya oleh mereka) tidak berarti bahwa hadis yang dimaksud redaksi dan maknanya benar-benar sama dalam kedua kitab rujukannya itu.

Kriteria hadis muttafaq 'alaih dalam suatu kitab himpunan hadis ternyata sangat

\footnotetext{
${ }^{3}$ Hadis pertama dalam kitab Riyadh al-Shalihin dan Al-Arba in al-Nawawiyyah adalah hadis Innama ala`mal bi al-niyyat yang diriwayatkan oleh AlBukhari dan Muslim.
}

ditentukan oleh prinsip penulisnya dalam beberapa tema ilmu hadis, yaitu tema periwayatan hadis dengan makna, memotong atau meringkas hadis, dan penggabungan dua hadis.

\section{Teori Al-Nawawi Tentang Hadis Muttafaq `Alaih}

Berkenaan dengan hal tersebut AlNawawi tampaknya termasuk ulama yang memperbolehkan periwayatan hadis dengan makna dan peringkasan hadis, sebagaimana yang dinyatakan dalam kitab Taqrib-nya sebagai berikut,

$$
\begin{aligned}
& \text { وقال جمهور السلف والخلف من الطوائف: يجوز بالمعنى } \\
& \text { في جميعه إذا قطع بأداء المعنى وهذا في غير المصنفات، } \\
& \text { ولا يجوز تغيير مصنف وإن كان بمعناه والله أعلم وينبغي } \\
& \text { للراوي بالمعنى أن يقول عقيبه: أو كما قال أو نحوه، أو } \\
& \text { شبهه، أو ما أشبه هذا من الألفاظ }
\end{aligned}
$$

Mayoritas ulama, salaf dan khalaf, dari berbagai disiplin ilmu menyatakan, "Boleh meriwayatkan hadis secara makna apabila dipastikan dapat mengungkap maknanya. Hal ini berlaku untuk periwayatan dari selain kitab yang telah disusun dengan final. Tidak boleh mengubah redaksi suatu kitab, meskipun dengan makna yang sama. Wallahu a lam. Sebaiknya seorang periwayat hadis secara makna setelah meriwayatkan hadis tersebut mengatakan "Aw kamâ qâla" atau "Nahwahu" atau "Syibhahu" atau lafal lain yang semakna. ${ }^{4}$

Teori ini menunjukkan bahwa boleh jadi redaksi hadis muttafaq 'alaih antara yang di dalam Shahih al-Bukhari dan di dalam Shahih Muslim berbeda, tapi menggunakan

4 Al-Nawawi, Al-Taqrib wa al-Taysir, 15. 
kata-kata yang memiliki maknanya sama (muradif/sinonim). Aplikasi teori ini adalah boleh mengutip salah satu hadis yang demikian dengan tanpa menjelaskan lebih jauh dari sumber manakah redaksi tersebut dikutip. Akan tetapi lebih baik sumber kutipan tersebut dijelaskan.

Al-Nawawi juga membolehkan peringkasan hadis bagi orang yang memahami betul maksud hadis yang bersangkutan, sehingga ia mengetahui katakata yang harus disertakan dan kata-kata yang dapat ditinggalkan tanpa merusak makna dan tidak mengurangi petunjuknya. ${ }^{5}$ Hal ini menunjukkan bahwa hadis-hadis muttafaq 'alaih yang redaksinya banyak dan berbeda-beda dapat disusun ulang dalam satu redaksi yang mewakili seluruh redaksi lainnya.

Tampaknya teori terakhir ini diaplikasikan Al-Nawawi ketika menuliskan hadis innama al-a 'mal bi al-niyyat di awal kitab Riyadh alShalihin $^{6}$ dan Al-Arba in al-Nawawiyyah, karena hadis yang redaksinya persis seperti itu tidak terdapat dalam Shahih al-Bukhari maupun dalam Shahih Muslim, melainkan merupakan hasil penyusunan ulang dengan memasukkan sebagian redaksi satu hadis ke dalam redaksi hadis lainnya.

Apabila ada satu hadis dari dua orang atau lebih yang berbeda redaksinya, maka menurut Al-Nawawi boleh digabungkan sanadnya dengan menjelaskan dari siapakah redaksi yang ditulis itu dikutip. ${ }^{7}$ Sehubungan dengan itu hadis yang diriwayatkan oleh AlBukhari dan Muslim dan berbeda redaksinya dapat juga disebut sebagai muttafaq `alaih. Hanya saja hendaknya pada saat dikutip ke

\footnotetext{
5 Al-Nawawi, Al-Taqrib wa al-Taysir, 15.

${ }^{6}$ Hadis ini akan dibahas pada awal bab III.

7 Al-Nawawi, Al-Taqrib wa al-Taysir, 16.
}

dalam kitab himpunan hadis disebutkan sumber aslinya.

Hal ini secara ilmu hadis riwayah menyalahi kode etik periwayatan hadis. Pengutipan hadis dari satu kitab ke dalam kitab lain merupakan satu bentuk periwayatan hadis, sehingga tidak dibenarkan apabila menyalahi atau mengubah redaksi aslinya. Artinya apabila seseorang mengutip suatu hadis dari Shahih al-Bukhari dan Shahih Muslim lalu memberinya simbol muttafaq ‘alaih, namun redaksi yang sama tidak ditemukan dalam kedua kitab tersebut atau salah satunya, maka pengutipannya telah melanggar kode etik pengutipan hadis yang telah ditetapkan para ahli hadis, karena mereka menyatakan periwayatan hadis dari kitab harus secara lafal. ${ }^{8}$ Al-Nawawi yang menulis Riyadh al-Shalihin dan Ibn Hajar AlAsqalani yang menulis Bulugh al-Maram merupakan imam ahli hadis dengan karya di bidang ilmu hadis yang sangat dihargai, yaitu Al-Taqrib wa al-Taysir karya Al-Nawawi dan Nukhbat al-Fikr dengan syarahnya Nuzhat al-Nazhar karya Ibn Hajar. Oleh karena itu, mereka tidak layak melakukan kesalahan dalam mengutip hadis yang diberinya simbol muttafaq `alaih dengan melanggar kode etik periwayatan hadis.

Apabila seseorang melakukan kesalahan dalam mengutip hadis yang diberinya simbol muttafaq `alaih dalam arti hasil kutipannya itu tidak terdapat dalam kitab Shahih alBukhari dan Shahih Muslim atau salah satunya ${ }^{9}$ atau hadis yang dikutip itu terdapat dalam kedua kitab tersebut atau salah satunya, tapi merupakan hadis yang padanya

\footnotetext{
${ }^{8}$ Nuruddin 'Itr, Manhaj al-Naqd fì 'Ulûm alHadîts, 228.

9 Seperti Al-Nawawi dalam mengutip hadis Innama al-a 'mal bi al-niyyat di awal kitab Al-Arba'în al-Nawaiyyah dan Riyâdh al-Shâlihîn.
} 
terdapat indikasi kelemahan dengan meninggalkan hadis serupa yang tidak terdapat indikasi kelemahan padanya, ${ }^{10}$ maka hasil kutipannya adalah lemah sehingga tidak dibenarkan untuk dikutip ulang.

\section{SIMPULAN}

1. Al-Nawawi dalam menulis kitab Riyadh al-Shalihin berkomitmen untuk menuliskan hadis-hadis shahih dari alkutub al-shahihat al-masyhurat (kitab induk hadis yang masyhur), sehingga ia banyak mengutip hadis-hadis muttafaq 'alaih, yaitu hadis yang terdapat dalam kitab Shahih al- Bukhari dan Shahih Muslim , dengan porsi separoh dari seluruh hadisnya yang berjumlah 1896 hadis.

2. Dilihat dari keterpenuhan kriteria hadis muttafaq `alaih, maka hadis-hadis muttafaq `alaih dalam Riyadh al-Shalihin dapat dikagorisasikan menjadi empat, yaitu a) hadis-hadis yang redaksinya benar-benar sama dengan redaksinya dalam Shahih al-Bukhari dan Shahih Muslim sebesar $52 \%$, b) hadis-hadis yang redaksinya hanya sama sama dengan redaksinya dalam Shahih alBukhari sebesar $19 \%$, c) hadis-hadis yang redaksinya hanya sama dengan

\footnotetext{
${ }^{10}$ Muhammad Fu'ad 'Abd al-Baqi dalam mengutip hadis tentang shalat dua rakaat sebelum shubuh pada hadis No. 419 dari Al-Lu'lu' wa al-Marjan (I: 141), yaitu hadis berikut,

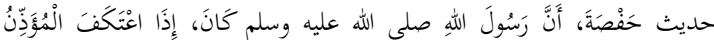

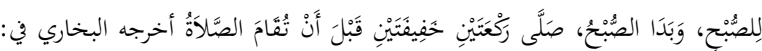$$
10 \text { كتاب الأذان: } 12 \text { باب الأذان بعد الفجر }
$$

Ibn Hajar dalam mensyarah hadis ini menyatakan bahwa lafal "idzâ i takafa" merupakan lafal muharraf dari lafal "idzâ sakata". Lihat Fath al-Bari bi Syarh Shahih al-Bukhari tahqiq Abd al-Qadir Syaibat alHamd, Cet. Al-Amir Sulthan bin Abd al-'Aziz Alu Sa`ud, Riyadh, 1412 H, jilid II, 121.
}

redaksinya dalam Shahih Muslim sebesar $17 \%$, d) hadis-hadis yang redaksinya tidak sama dengan redaksinya dalam Shahih al-Bukhari dan Shahih Muslim sebesar $12 \%$.

\section{DAFTAR PUSTAKA}

'Asqalani, Ahmad bin Ali bin Hajar Al-. Fath al-Bari Syarh Shahih Al-Bukhari. Saudi Arabia: Ri'asat Idarat al-Buhuts Al'Ilmiyyah wa Al-Ifta' wa Al-Da`wah, t.t. 'Itr, Nuruddin Fî Zhilâl al-Hadîts al-Nabawi: Dirasast Fikriyyah Ijtima iyyah wa Adabiyyah Jamaliyyah Mu'ashirah, t.p., 2000.

Abadi, Muhammad Syamsul Haqq Al‘Azhim, `Awn al-Ma`bâd Syarh Sunan Abî Dâwûd. Al-Maktabah Al-Salafiyyah, 1979.

Asyqar, Muhammad Sulaiman Al-. Af al alRasul Saw. wa Dilalatuha 'ala al-Ahkam al-Syar`iyyah. Kuwait: Al-Manar AlIslamiyyah, 1878.

Bukhari, Muhammad bin Ismail Al-, Shahih al-Bukhari. Beirut: Dar al-Fikr, 1405 H.

Busti, Abu Sulaiman Hamd bin Muhammad Al-Khaththabi Al-. Ma`alim al-Sunan Syarh Sunan Abi Dawud. Beirut: AlMaktabah Al-'Ilmiyyah, 1981.

Ghazali, Abu Hamid Al-, Al-Mustashfa, Dar al-Kutub al-'Ilmiyyah, Beirut, $1413 \mathrm{H}$.

Ghazali, Muhammad, Kritik Atas Hadis Nabi Saw., Bandung : Mizan, Cet. II,1992.

Ibn Qutaibah, Abu Muhammad Abdullah bin Muslim. Ta'wîl Mukhtalif al-Hadîts, Dar al-Jil, Beirut, 1972.

Ismail, M. Syuhudi. Hadis Nabi Yang Tekstual dan Kontekstual; Telaah Ma`ani al-Hadits Tentang Ajaran Islam Yang Universal, Temporal, dan Lokal, Jakarta, Bulan Bintang, Cet. I, 1994. 
Kandahlawi, Maulana Muhammad Zakariyya Al-. Aujaz al-Masalik, Dar al-Fikr, Beirut, 1989.

Khan, Muhammad Mushthafa Sa id al(et.al.), Nuz-hat al-Muttaqîn Syarh Risyâdh al-Shalihîn Min Kalâm Sayyid alMursalîn, Mu'assasah Al-Risalah, Beirut, 1993.

Maliki, Al-Hafizh Ibn al-'Arabi Al-. 'Aridhat al-Ahwadzi bi Syarh Shahih Al-Turmudzi, Dar al-Fikr, t.t.

Mubarakfuri, Muhammad Abdurrahman bin Abdurrahim Al-, Tuhfat al-Ahwadzi Syarh Jâmi al-Turmudzi, Dar al-Fikr, t.t.

Naisaburi, Muslim bin Al-Hajjaj Al-, Shahih Muslim. Maktabah Dahlan, Bandung, t.t.p.
Nawawi, Muhyiddin Abu Zakariya Yahya bin Syaraf Al-, Syarh Shahih Muslim, Dar al-Fikr, t.t.

Qaradhawi, Yusuf Al-. Kaifa Nata'âmalu ma`a Al-Sunnah Al-Nabawiyyah Ma'âlim wa Dhawâbith. diterjemahkan oleh. Muhammad Al-Baqir, Bandung: Karisma 1993.

Syawkaniy, Muhammad bin Ali bin Muhammad Al-, Nayl al-Awthar Syarh Muntaqa al-Akhbar Tahqiq Shidqi Muhammad Jamil al-'Aththar, Lebanon: Dar al-Fikr, 1994. 
